\title{
Inhalation and dermal exposure to atmospheric polycyclic aromatic hydrocarbons and associated carcinogenic risks in a relatively small city
}

\author{
Elif Gungormus ${ }^{\mathrm{a}, \mathrm{b}}$, Semra Tuncel ${ }^{\mathrm{c}}$, Lokman Hakan Tecer ${ }^{\mathrm{d}, * * *}$, Sait C. Sofuoglu ${ }^{\mathrm{a}, \mathrm{b}, *}$ \\ a Izmir Institute of Technology, Environmental Engineering Graduate Program, Gulbahce, Urla 35430 Izmir, Turkey \\ ${ }^{\mathrm{b}}$ Izmir Institute of Technology, Department of Chemical Engineering, Gulbahce, Urla 35430 Izmir, Turkey \\ c Middle East Technical University, Department of Chemistry, 06800 Ankara, Turkey \\ d Namik Kemal University, Department of Environmental Engineering, 59860 Corlu, Tekirdag, Turkey
}

\section{A R T I C L E I N F O}

Article history:

Received 20 March 2014

Received in revised form

13 June 2014

Accepted 14 June 2014

Keywords:

Polycyclic aromatic hydrocarbons

Exposure

Carcinogenic risk

Balikesir

\begin{abstract}
A B S T R A C T
The aim of this study was to conduct a carcinogenic risk assessment for exposure to polycyclic aromatic hydrocarbons (PAHs) via routes of inhalation and dermal contact. Concentrations of $19 \mathrm{PAH}$ species were determined during a heating period at a site in the city of Balikesir, Turkey. Two questionnaires were administered to a sample of inhabitants to determine time-activity budgets and demographic information. The assessment was conducted for each participant and Balikesir population by deterministic and probabilistic approaches, respectively. Monte Carlo simulation was implemented to determine the population exposure-risk probability distributions. The estimates were based on benzo[a]pyrene equivalent $\left(\mathrm{BaP}_{\mathrm{eq}}\right)$ total $\mathrm{PAH}$ concentrations calculated using toxic equivalency factors. The mean and median $\mathrm{BaP}_{\text {eq }}$ concentrations of gaseous and particulate phases were 3.25 and 1.34 , and 38.5 and $34.0 \mathrm{ng} / \mathrm{m}^{3}$, respectively. Carcinogenic risk for inhalation exposure route was estimated by using two different slope factor values ( 3.9 and $\left.304.5(\mathrm{mg} / \mathrm{kg} \text {-day })^{-1}\right)$, recommended by two different organizations, resulting in two (order(s) of magnitude apart) population risk ranges: $1.32 \times 10^{-7}-2.23 \times 10^{-4}$, and $1.61 \times 10^{-5}-7.95 \times 10^{-3}$, respectively. The population risks associated with dermal exposure were lower compared to those of inhalation, ranging from $6.58 \times 10^{-9}$ to $2.57 \times 10^{-6}$. The proportion of the population with risks higher than the general acceptable level $\left(1.0 \times 10^{-6}\right)$ was estimated as $>99$ percent, for inhalation, and as 28 percent for dermal exposure route.
\end{abstract}

(c) 2014 Elsevier Inc. All rights reserved.

\section{Introduction}

Polycyclic Aromatic Hydrocarbons (PAHs) are the most frequently detected semi-volatile organic compounds (SVOCs) in ambient air with higher concentrations compared to other common groups of SVOCs (such as polychlorinated biphenyls and polybrominated diphenyl ethers). PAHs and their derivatives are known to be generated by incomplete combustion of organic materials and fossil fuels (Li et al., 2013). Therefore, there are abundant number of sources such as motor vehicles and residential heating, resulting in high ambient air concentrations in urban areas, especially mega

\footnotetext{
* Corresponding author at: Izmir Institute of Technology, Department of Chemical Engineering, Gulbahce, Urla 35430 Izmir, Turkey. Tel.: +90232750 6648; fax: +902327506645.

** Corresponding author. Tel.: +90 282250 2438; fax: +90 2826529372.

E-mail addresses: lhtecer@nku.edu.tr (L. Hakan Tecer), cemilsofuoglu@iyte.edu.tr, saitcemil@iit.edu (S.C. Sofuoglu).
}

cities. PAHs have many adverse health effects. After chronic exposure to PAHs, damage of organ systems, cancer, reproductive effects can occur. Although presence of more than $100 \mathrm{PAH}$ compounds in nature are known, 16 of them have been accepted as priority compounds because of their high carcinogenic and toxic effects. The list includes naphthalene (Nap), acenaphthylene (AcPy), acenaphthene (Acp), fluorene (Flu), phenanthrene (PA), anthracene (Ant), fluoranthene (FL), pyrene (Pyr), benzo[a]anthracene $(\mathrm{BaA})$, chrysene (Chry), benzo[b]fluoranthene (BbF), benzo[k]fluoranthene (BkF), benzo[a]pyrene (BaP), indeno[1,2,3-c,d]pyrene (Ind), dibenzo [a,h]anthracene (DahA), benzo[g,h,i]perylene (BghiP) (USEPA, 2010). Among the 16 compounds, BaP is determined as the most important carcinogenic PAH compound. Thus, it is accepted as model compound in cancer studies (Luch and Baird, 2010; Akcha et al., 2003). Since PAH compounds have different level of carcinogenic effects, three approaches were developed in order to estimate the risk of a PAH mixture, and to prevent overestimation of carcinogenic risk (Jung et al., 2010). These approaches are Toxic 
Equivalency Factors (TEFs), the comparative potency of mixtures, and the use of BaP as a surrogate (Pufulete et al., 2004; IPCS, 1998).

Health risk assessments were conducted for PAH compounds in urban areas around the world because of their high atmospheric concentrations. To date, information on $\mathrm{PAH}$ air pollution in Turkey is limited. In the limited number of studies that exist, high atmospheric PAH concentrations have been measured in several locations such as Bursa (Esen et al., 2006; Birgul et al., 2011), Eskisehir (Ari, 2008), Istanbul (Hanedar et al., 2011), Izmir (Demircioglu et al., 2011), and Konya (Ozcan and Aydin, 2009) which are large cities, smallest of which with a metropolitan population of 630,000 (TUIK, 2010); Aliaga (Bozlaker et al., 2008; Kaya et al., 2012) and Iskenderun (Ozgunerge Falay et al., 2013) which are locations of intense industrial activity; Kocaeli (Gaga et al., 2012) a large city with intense industrial activity; and Zonguldak (Akyuz and Cabuk, 2008), a relatively small city with a population of about 109,000 (TUIK, 2010) but that has intense coal mining activity and iron-steel industry about $15 \mathrm{~km}$ far away. Nevertheless, only one study conducted an exposure-risk assessment (Gaga et al., 2012), which estimated $>1.0 \times 10^{-3}$ total cancer risk levels using the unit risk approach.

The objective of this study was to assess health risk levels for inhalation and dermal contact exposure to ambient air PAHs in a relatively small city, Balikesir, Turkey, where residential heating and traffic are the only major PAH sources. Urban atmospheric $\mathrm{PAH}$ concentrations were measured in a heating period, and timeactivity information of a sample of Balikesirians were collected to estimate the individual carcinogenic risks. A Monte Carlo simulation was conducted to estimate the population risks, for which sensitivity and uncertainity analyses were also conducted.

\section{Materials and methods}

\subsection{Sampling site}

Balikesir is a city in western Turkey, with a population of approximately 266,000 (TUIK, 2010). Agriculture is the main economy driver. Some small and medium scale industrial enterprises are spread to districts, e.g., production of transformers, paper, cement, marble, metal products, agricultural machinery, electrical equipment, man-made fabrics, and fertilizer. Samples were collected at a station (Necatibey Egitim Fakultesi) in the downtown campus of Balikesir University, which is located between the city center and the residential areas. Therefore, the sampling site should reflect both of the areas.

The city's climate is a transitional climate between the Mediterranean and the Balkan. The average temperature during sampling period was $10.5^{\circ} \mathrm{C}$, while the annual average temperature is $14.6^{\circ} \mathrm{C}(1980-2006)$ (Turkish State Meteorological Service, 2014). The northern cold weather systems during the winter and the southern hot and dry weather during the summer influence the city (Koc, 2001; Tagll, 2004). Residental heating is fueled by natural gas and coal with roughly 40 and 60 percent contribution, respectively.

\subsection{Sample collection and analysis}

PAH samples were collected on a diurnal basis $(n=26)$ during the heating period between October 2009 and March 2010 at a station located in the downtown campus of Balikesir University. Particle and gas phase samples were collected on glass wool filters (GWF), and polyurethane foam (PUF), respectively, with a high volume sampler model GPS II (Thermo-Andersen Inc.) collecting $300 \mathrm{~m}^{3}$ of air per sample. Gas phase air samples (PUF cartridges) were Soxhlet extracted for $24 \mathrm{~h}$ with a mixture of 1:4 dichloromethane (DCM):petroleum hexane. Particle phase air samples (GWF) were ultrasonically extracted for $30 \mathrm{~min}$ with DCM. Prior to extraction, all samples were spiked with $\mathrm{PAH}$ surrogate standards to monitor the analytical recovery efficiencies. After concentrating the extracts of PUF cartridges to $10 \mathrm{~mL}$ and the extracts of GWF to $5 \mathrm{~mL}$ using a rotary evaporator, samples were cleaned up and fractionated on a florisil column with a mixture of 1:4 hexane: toluene. PAHs were eluted, and concentrated under a stream of $\mathrm{N}_{2}$ to $1 \mathrm{~mL}$ in hexane. Gas chromatography-mass spectrometry (GC-MS) was used to detect and quantify $\mathrm{PAH}$ compounds in the collected samples after the preparation procedure (extraction, clean up, concentration). Selective ion monitoring mode (SIM) was used for analysis. Details regarding sampling and analysis can be found elsewhere (Tecer et al., 2012). Concentrations of 19 PAH species were determined. These were
Nap, AcPy, Acp, Flu, PA, Ant, FL, Pyr, BaA, Chyr, BbF, BkF, BaP, Ind, DahA, BghiP, benzo [e]pyrene (BeP), cyclo-penta[c,d]pyrene (CYC), anthanthrene (ATT).

Field blanks were collected and analyzed to determine background contamination. All blank levels were $<10$ percent of the samples. Sample concentrations were blank corrected. Limits of Detection were calculated by adding three standard deviations to the mean blank levels, which ranged from $0.007 \mathrm{ng} / \mathrm{m}^{3}$ for Chyr to $0.052 \mathrm{ng} / \mathrm{m}^{3}$ for BkF. Average recoveries were calculated using the surrogate standards, which ranged from 75 percent for Nap, AcPy, Acp, and FL to 90 percent for BbF, Ind, DahA, BgP, BaP, BkF, Flt, Pyr, BaA, and Chyr. A standard reference material (SRM 1649a) was also used to check the analytical method. The average recoveries from the SRM were > 97 percent for Ant, FL, Pyr, BaA, Chyr, and BaP, and ranged between 83 percent (Nap) and 94 percent (BgP) for the remaining compounds.

\subsection{Questionnaires}

Time-activity budgets and demographic information were collected from 63 participants in the city by administering two questionnaires. The first questionnaire, which inquired about demographics of occupants, was administered by the investigators during a visit to their households. The second questionnaire was selfadministered by the primary participant for a week. Demographic data collected included gender, age, education, income, homeland, and body weight. Time-activity questionnaire aimed to collect the time daily spent with five different activity levels of rest, sedentary, light, moderate, and heavy activity. Primary participants were asked to keep track of the time spent with different activities during the day, and administer the questionnaire at night. Seven-day averages were calculated for each participant for use in exposure-risk assessment.

\subsection{Exposure assessment}

Exposure assessment was conducted for inhalation and dermal contact routes. Chronic daily intake (CDI) was calculated (USEPA, 1997) as an estimate of inhalation exposure for each PAH compound $(i)$ and activity category $(j)$ :

$$
i C D I_{i, j}=\frac{C_{i} \times I R_{j} \times E D_{j} \times E F}{B W \times A T}
$$

where $C$ is the contaminant concentration $\left(\mathrm{ng} / \mathrm{m}^{3}\right), I R$ is inhalation rate $\left(\mathrm{m}^{3} /\right.$ day), $E D$ is exposure duration (yr), $E F$ is exposure frequency (days/yr), $B W$ is body weight $(\mathrm{kg})$, $A T$ is averaging time which was assumed as lifetime and calculated as $E D \times 365$ days/yr, and $i C D I$ is inhalation chronic daily intake ( $\mathrm{ng} / \mathrm{kg}$-day). Lifetime exposure was assumed for the assessment ( $E D=70$ years). Since samples were collected only in a heating period, the data represented one half of a year, and $E F$ was taken as 180 days/yr. A conservative approach was chosen by assuming a 100 percent penetration of outdoor air into the buildings resulting in equal indoor and ambient air concentrations. The mean $[ \pm S D$ ] penetration used for homes of an urban area in a population PAH exposure-risk study (90 $[ \pm 6]$ percent, Zhou and Zhao, 2014) shows that the above assumption would not introduce considerable error into the estimated risks because the uncertainty level only in the measured PAH concentrations are $>10$ percent, e.g., average recovery efficiency of sample extraction procedure ranges from 60 to 86 percent which are acceptable by the standard method EPA TO 13A (Demircioglu et al., 2011; Gaga et al., 2012). Furthermore, the mean $\mathrm{BaP}_{\mathrm{eq}}$ concentration indoor/outdoor ratio reported for homes of the urban area (Zhou and Zhao, 2012) ranged from 0.94 to 1.11 (5th to 95th percentile). BaP is assumed as model compound for PAH mixture. Thus, all concentrations of $\mathrm{PAH}$ compounds were expressed by $\mathrm{BaP}_{\mathrm{eq}}$ which was calculated based on the set of TEFs proposed by Nisbet and LaGoy (1992) and Larsen and Larsen (1998), shown in Table 1 . The proposed values were based on the available literature on carcinogenity with various routes of exposure.

Exposure by dermal contact was calculated as (USEPA, 1992)

$d C D I=\frac{C \times K_{p} S \times S A \times E D \times E F}{B W \times A T}$

where $C$ is the contaminant concentration $\left(\mathrm{ng} / \mathrm{m}^{3}\right), K_{p} s$ is permeability coefficient $\left(\mathrm{m} /\right.$ day), $S A$ is exposed body surface area $\left(\mathrm{m}^{2}\right), E D$ is exposure duration $(\mathrm{yr}), E F$ is the exposure frequency (day/yr), $A T$ is averaging time (yr), $B W$ is the body weight $(\mathrm{kg})$, and $d C D I$ is chronic daily intake (ng/kg-day). $A T, E D$, and $E F$ were assumed as the same values as in Eq. 1. Particle phase concentrations were determined for each $\mathrm{PAH}$ compound, and the concentrations were used as contaminant concentrations (C) in Eq. (2). Total body surface area was estimated in relation to the body weights obtained from the questionnaire using Eq. (3) (Livingston and Lee, 2001)

$S A=0.1173 \times B W^{0.6466}$

where $B W$ is the body weight $(\mathrm{kg}), S A$ is total body surface area $\left(\mathrm{m}^{2}\right)$. The body segments including only hands ( 2.7 percent of SA) and heads ( 4.0 percent of SA) were considered in $d C D I$ calculation, because other body segments were covered by clothes in the sampling period.

\subsection{Risk assessment}

An individual health risk assessment was conducted for the participants of this study for both inhalation and dermal contact exposure routes. In addition, a 
Table 1

Proposed TEFs for individual PAHs.

\begin{tabular}{lllllll}
\hline Compound & $\begin{array}{l}\text { Nisbet and } \\
\text { LaGoy } \\
(1992)\end{array}$ & $\begin{array}{l}\text { OEHHA } \\
(1994)\end{array}$ & $\begin{array}{l}\text { Muller } \\
(1997)\end{array}$ & $\begin{array}{l}\text { Malcolm } \\
\text { and Dobson } \\
(1994)\end{array}$ & $\begin{array}{l}\text { Larsen and } \\
\text { Larsen } \\
(1998)\end{array}$ & $\begin{array}{l}\text { This } \\
\text { Study }\end{array}$ \\
\hline Nap & 0.001 & - & - & - & - & $0.001^{\mathrm{a}}$ \\
AcPy & 0.001 & - & - & 0.001 & - & $0.001^{\mathrm{a}}$ \\
Acp & 0.001 & - & - & 0.001 & - & $0.001^{\mathrm{a}}$ \\
Flu & 0.001 & - & - & - & - & $0.001^{\mathrm{a}}$ \\
PA & 0.001 & - & 0.00064 & 0.001 & 0.0005 & $0.001^{\mathrm{a}}$ \\
Ant & 0.01 & - & - & 0.01 & 0.0005 & $0.01^{\mathrm{a}}$ \\
FL & 0.001 & - & - & 0.001 & 0.05 & $0.001^{\mathrm{a}}$ \\
Pyr & 0.001 & - & 0 & 0.001 & 0.001 & $0.001^{\mathrm{a}}$ \\
CYC & - & - & 0.012 & - & 0.02 & $0.02^{\mathrm{b}}$ \\
BaA & 0.1 & 0.1 & 0.014 & 0.1 & 0.005 & $0.1^{\mathrm{a}}$ \\
Chry & 0.01 & 0.01 & 0.026 & 0.01 & 0.03 & $0.01^{\mathrm{a}}$ \\
BbF & 0.1 & 0.1 & 0.11 & 0.1 & 0.1 & $0.1^{\mathrm{a}}$ \\
BkF & 0.1 & 0.1 & 0.037 & 0.1 & 0.05 & $0.1^{\mathrm{a}}$ \\
BaP & 1 & 1 & 1 & 1 & 1 & $1^{\mathrm{a}}$ \\
BeP & - & - & 0 & 0.01 & 0.002 & $0.002^{\mathrm{b}}$ \\
Ind & 0.1 & 0.1 & 0.067 & 0.1 & 0.1 & $0.1^{\mathrm{a}}$ \\
DahA & 1 & - & 0.89 & 1 & 1.1 & $1^{\mathrm{a}}$ \\
BghiP & 0.01 & - & 0.012 & 0.01 & 0.02 & $0.01^{\mathrm{a}}$ \\
ATT & - & - & 0.28 & - & 0.3 & $0.3^{\mathrm{b}}$ \\
\hline
\end{tabular}

a The TEF values proposed by Nisbet and Lagoy (1992).

b The TEF values proposed by Larsen and Larsen (1998).

population health risk assessment was conducted using Monte Carlo simulation method. Cancer risk associated with PAH exposure is calculated using the following equation (USEPA, 2005)

$R=\sum_{j}^{J} C D I_{j} \times S F$

where $R$ is probability of excess cancer risk, $S F$ is slope factor of the chemical (ng/ $\mathrm{kg}$-day $)^{-1}, C D I_{j}$ is the chronic daily intake (ng/kg-day) for each activity, $j$. Two $S F$ values of 3.9 and $304.5(\mathrm{mg} / \mathrm{kg}-\text { day })^{-1}$ by CalEPA (2005) and WHO (1987), respectively, were used to calculate risk for inhalation; whereas, the $S F$ for dermal absorption route was $12.0(\mathrm{mg} / \mathrm{kg}-\text { day })^{-1}$ recommended by CalEPA (2005) for ingestion. Crystal Ball software (v 4.0e) was used to carry out Monte Carlo simulation to estimate population risks. The simulation is a computer-based method of analysis that uses statistical sampling techniques to obtain a probabilistic approximation to the output of a mathematical equation or a model. A probability distribution was used to depict the possible values for each variable in the exposure-risk model. Kolmogorov-Smirnov (KS), and Anderson-Darling (AD) tests were the aid to fit probability distributions to the measured data. The best fitting distribution was selected among beta, exponential, gamma, normal, lognormal, logistic, pareto, and Weibull distributions. The simulation was run for 10,000 trials producing 10,000 forecasts (or possible outcomes) which were used to construct distributions that describe population exposure and risk. A sensitivity analysis was also carried out by using the Crystal Ball software. In this study, rank correlation coefficients between each input and output were computed to rank the input parameters in terms of their effect on the output variables. Uncertainity analysis was also conducted using the simulation software. The bootstrap method was applied. Two hundred simulations were applied with 1000 trials each.

\section{Results}

\subsection{Ambient air PAH concentrations}

Gaseous phase and particle phase PAH concentrations were measured. Fig. 1 shows the gaseous and particle phase PAH and $\mathrm{BaP}_{\text {eq }}$ concentration profiles. The mean, median, and 95th percentile total PAH concentrations for gaseous phase were measured as 432,261 , and $1951 \mathrm{ng} / \mathrm{m}^{3}$, respectively. These statistics for total particle phase concentrations were 187,152 , and $499 \mathrm{ng} / \mathrm{m}^{3}$, respectively. The mean, median, and 95th percentile $\mathrm{BaP}_{\text {eq }}$ concentrations for gaseous phase were $3.25,1.34$, and $21.1 \mathrm{ng} / \mathrm{m}^{3}$, respectively. The $\mathrm{BaP}_{\text {eq }}$ concentrations for particle phase were measured as $38.5,34.0$, and $101 \mathrm{ng} / \mathrm{m}^{3}$, respectively.

\subsection{Exposure and risk assessment}

\subsubsection{Individual exposure and risks}

Individual exposures of the study participants were estimated using personal data from the questionnaires and the concentrations measured at the downtown station. Since concentrations were not specific to each participant, exposures were calculated for the mean, median, and 95th percentile $\mathrm{BaP}_{\text {eq }}$ concentrations. Table 2 presents the descriptive statistics of the estimated exposures for inhalation and dermal exposure routes. Inhalation exposure ranged between 1.5 and $7.0 \mathrm{ng} / \mathrm{kg}$-day, while dermal exposure ranged between 0.103 and $0.140 \mathrm{ng} / \mathrm{kg}$-day based on the mean $\mathrm{BaP}_{\mathrm{eq}}$ concentration. The majority of contribution to the total exposure (92-99 percent) is from the inhalation route.

Individual carcinogenic risk of the study participants were estimated with two different SFs which are by CalEPA (2005) and WHO (1987). Carcinogenic risks were calculated for inhalation and dermal exposure routes for the mean, median, and 95th percentile $\mathrm{BaP}_{\mathrm{eq}}$ concentrations. The risk level calculated on the basis of the mean concentration and SF by CalEPA (2005) ranged between $5.89 \times 10^{-6}$ and $2.74 \times 10^{-5}$, while the risk levels calculated on the basis of SF by WHO (1987) ranged between $4.60 \times 10^{-4}$ and $2.14 \times 10^{-3}$ for inhalation exposure. The risk level for dermal exposure ranged between $1.23 \times 10^{-6}$ and $1.68 \times 10^{-6}$. Descriptive statistics of the individual risk estimates are presented in Table 2.

\subsubsection{Population exposure and risks}

Monte Carlo simulation was implemented to estimate population exposure and risks for inhalation and dermal exposure routes. Fitted distributions for each input variable to the exposure-risk models, and their parameter values are presented in Table 3. The estimated inhalation exposures ranged between 0.037 to $24.4 \mathrm{ng} / \mathrm{kg}$-day, while the range for dermal exposure was from $3.7 \times 10^{-6}$ to $0.25 \mathrm{ng} / \mathrm{kg}$-day.

Estimated risk frequency histograms and fitted distributions for simulated population risks are shown in Fig. 2. The risk levels calculated on the basis of SF by CalEPA (2005) for inhalation exposure ranged between $1.32 \times 10^{-7}$ and $2.23 \times 10^{-4}$ (Fig. 2a), whereas the risk levels calculated using the $S F$ by WHO (1987) for inhalation exposure ranged between $1.61 \times 10^{-5}$ and $7.95 \times 10^{-3}$ (Fitted distribution: Gamma, Scale $=8.16 \times 10^{-4}$, Shape $=1.67$, Mean $=$ $1.36 \times 10^{-3}$, Median $=1.13 \times 10^{-3}, 95$ th percentile $\left.=3.33 \times 10^{-3}\right)$. Risk levels associated with dermal exposure ranged between $6.58 \times 10^{-9}$ and $2.57 \times 10^{-6}$ (Fig. 2b).

\section{Discussion}

Ambient air PAH samples were collected, and the profiles of gaseous and particle phase PAHs were determined. The concentration profiles of the two phases were different. The common and dominant PAHs for gaseous phase were PA and Nap, as shown in Fig. 1a. However, the dominant PAHs for particle phase were Ind, Pyr and FL (Fig. 1b). According to the literature, three-ring and four-ring PAH compounds are found in diesel exhaust particulates, especially PA, Pyr, FL (Rogge et al., 1993). PA can also be found abundantly in diesel exhaust vapor emissions (Westerholm and Li, 1994). Nap sources include coal combustion and burning of organic materials, such as fossil fuels and wood (ATSDR, 1995). Indeno[1,2,3-c,d]pyrene is found in gasoline engine exhaust and tobacco smoke (IARC, 1983). In conclusion, the dominant compounds of both of gaseous and particle phases were probably originated from coal combustion, burning of organic materials, gasoline or diesel engine exhaust emissions. 
A

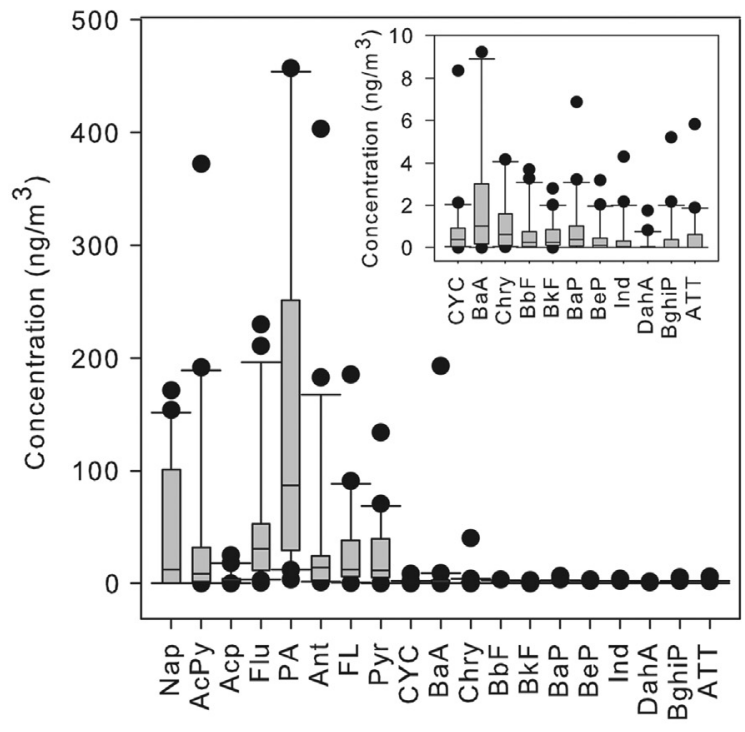

C

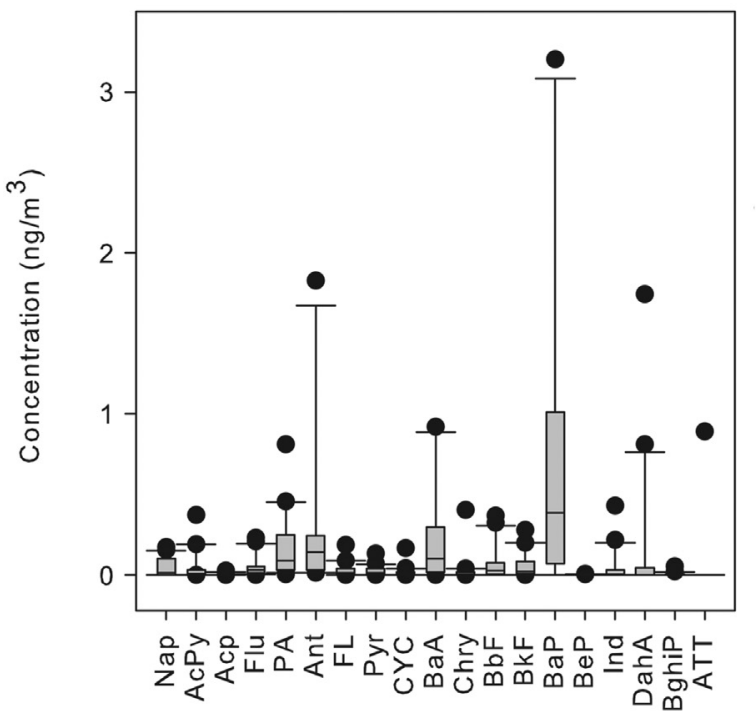

B

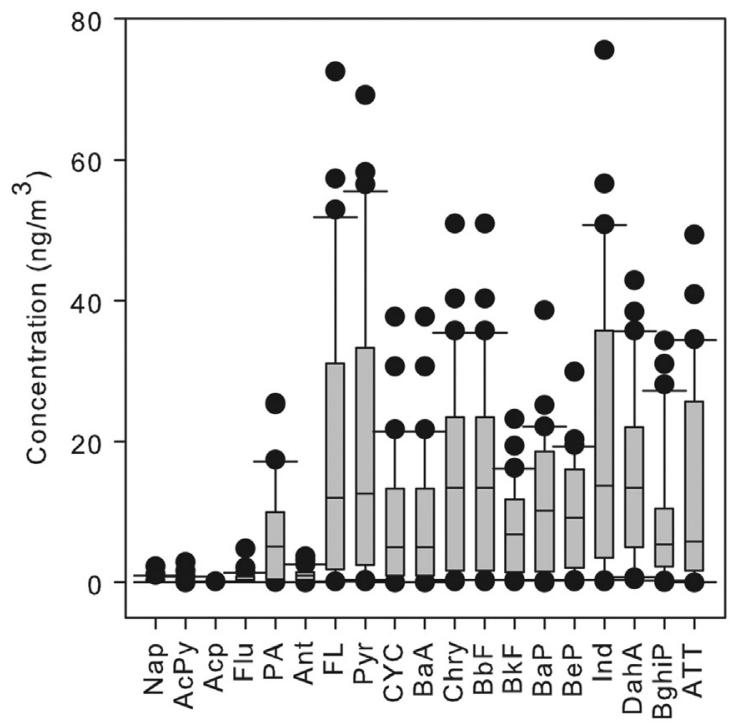

D

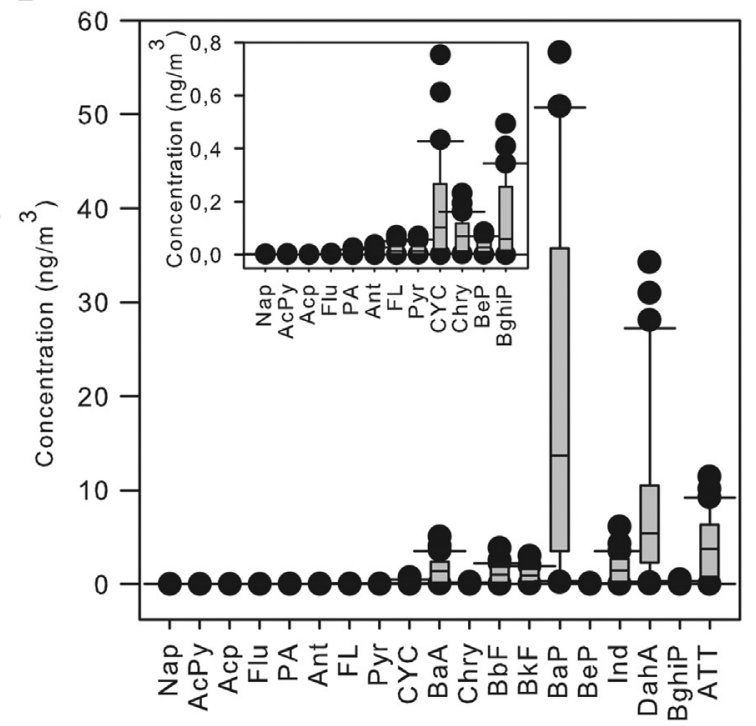

Fig. 1. PAH concentrations of (a) gaseous phase and (b) particle phase, (c) BaPeq concentrations of gaseous phase and (d) particle phase.

People spend majority of time indoors. The mean (and 5th to 95th percentile range) percentages of time spent indoors, outdoors, and in transit were 74 (63-83), 22 (11-35), and 3 (2-6), respectively, for the study participants. Therefore, exposure to $\mathrm{PAH}$ compounds indoors is important. There are indoor PAH sources such as cooking, tobacco smoking, and indoor heating (Zhou and Zhao, 2012) which may result in higher indoor air concentrations. However, the mean indoor/outdoor ratio for $\mathrm{BaP}_{\mathrm{eq}}$ concentration was reported to range from 0.94 to 1.11 (5th to 95th percentile). Moreover, reduction in the ambient air PAH concentrations was predicted to be the only method that would result in significant mitigation of risk for urban households (Zhou and Zhao, 2012). Consequently, the use of ambient air concentrations for exposure indoors in this study probably did not introduce a considerable error into the estimated risk levels.

Pufulete et al. (2004) reported that the use of TEFs is the more preferred method over the comparative potency of mixtures and the use of $\mathrm{BaP}$ as a surrogate for the determination of inhalation carcinogenic potencies of relevant PAHs in ambient air. In this approach, toxicity of each $\mathrm{PAH}$ compound is expressed relative to the toxicity of BaP, the most studied and potent PAH compound. Petry et al. (1996) reported that TEF values developed by Nisbet and LaGoy (1992) were proved to be a better set than the other published sets. Thus, PAH concentrations were converted to their BaP $_{\text {eq }}$ concentrations using the set by Nisbet and LaGoy (1992) in this study. However, values from Larsen and Larsen (1998) were also employed for those that are not in the set. The results showed that gaseous phase PAH concentrations were $>3.5$ times higher than that of particle phase, however, the particle phase $\mathrm{BaP}_{\mathrm{eq}}$ concentrations were at least 4 times higher than gaseous phase $\mathrm{BaP}_{\text {eq }}$ concentrations. This is because the gaseous phase $\mathrm{PAH}$ compounds have lower molecular weights and TEF values than the particle phase $\mathrm{PAH}$ compounds. The $\mathrm{BaP}_{\mathrm{eq}}$ concentrations measured in this study are similar to those measured in Kocaeli, Turkey (Gaga et al., 2012), are in the range of those measured in Asian countries (Chang et al., 2006), lower than those measured at road intersections in Tianjin, China (Hu et al., 2007) and at a highway toll station in Taiwan (Tsai et al., 2004), higher than those measured in in Zaragoza, Spain (Callen et al., 2007) and in the UK (Delgado-Saborit et al., 2011). 
Table 2

Descriptive statistics for individual exposure (ng/kg-day) and carcinogenic risks.

\begin{tabular}{|c|c|c|c|c|c|c|c|}
\hline Inhalation route & & Min & Median & Mean & Standard deviation & 95th Percentile & Max \\
\hline \multirow{3}{*}{ Based on mean $\mathrm{BaP}_{\mathrm{eq}}$ concentration } & Exposure & 1.5 & 4.1 & 4.2 & 1.1 & 5.8 & 7.0 \\
\hline & Risk $^{\mathrm{a}}$ & $5.89 \times 10^{-6}$ & $1.60 \times 10^{-5}$ & $1.63 \times 10^{-5}$ & $4.18 \times 10^{-6}$ & $2.25 \times 10^{-5}$ & $2.74 \times 10^{-5}$ \\
\hline & Risk $^{\mathrm{b}}$ & $4.60 \times 10^{-4}$ & $1.25 \times 10^{-3}$ & $1.27 \times 10^{-3}$ & $3.27 \times 10^{-4}$ & $1.76 \times 10^{-3}$ & $2.14 \times 10^{-3}$ \\
\hline \multirow{4}{*}{ Based on median $\mathrm{BaP}_{\mathrm{eq}}$ concentration } & Exposure & 1.0 & 2.8 & 2.9 & 0.7 & 4.0 & 4.8 \\
\hline & Risk $^{\mathrm{a}}$ & $4.05 \times 10^{-6}$ & $1.10 \times 10^{-5}$ & $1.12 \times 10^{-5}$ & $2.88 \times 10^{-6}$ & $1.55 \times 10^{-5}$ & $1.89 \times 10^{-5}$ \\
\hline & Risk $^{\mathrm{b}}$ & $3.16 \times 10^{-4}$ & $8.58 \times 10^{-4}$ & $8.74 \times 10^{-4}$ & $2.25 \times 10^{-4}$ & $1.21 \times 10^{-3}$ & $1.47 \times 10^{-3}$ \\
\hline & Exposure & 5.8 & 15.8 & 16.0 & 4.1 & 22.3 & 27.2 \\
\hline \multirow{2}{*}{ Based on 95th percentile $\mathrm{BaP}_{\mathrm{eq}}$ concentration } & Risk $^{\mathrm{a}}$ & $2.27 \times 10^{-5}$ & $6.17 \times 10^{-5}$ & $6.28 \times 10^{-5}$ & $1.62 \times 10^{-5}$ & $8.69 \times 10^{-5}$ & $1.06 \times 10^{-4}$ \\
\hline & Risk $^{\mathrm{b}}$ & $1.78 \times 10^{-3}$ & $4.82 \times 10^{-3}$ & $4.91 \times 10^{-3}$ & $1.26 \times 10^{-3}$ & $6.78 \times 10^{-3}$ & $8.27 \times 10^{-3}$ \\
\hline Dermal route & & Min & Median & Mean & Standard deviation & 95th Percentile & Max \\
\hline \multirow[b]{2}{*}{ Based on mean $\mathrm{BaP}_{\mathrm{eq}}$ concentration } & Exposure & 0.103 & 0.120 & 0.121 & 0.008 & 0.135 & 0.140 \\
\hline & Risk & $1.23 \times 10^{-6}$ & $1.47 \times 10^{-6}$ & $1.46 \times 10^{-6}$ & $9.02 \times 10^{-8}$ & $1.62 \times 10^{-6}$ & $1.68 \times 10^{-6}$ \\
\hline \multirow{2}{*}{ Based on median $\mathrm{BaP}_{\mathrm{eq}}$ concentration } & Exposure & 0.090 & 0.107 & 0.106 & 0.007 & 0.118 & 0.122 \\
\hline & Risk & $1.08 \times 10^{-6}$ & $1.28 \times 10^{-6}$ & $1.27 \times 10^{-6}$ & $7.88 \times 10^{-8}$ & $1.42 \times 10^{-6}$ & $1.47 \times 10^{-6}$ \\
\hline \multirow{2}{*}{ Based on 95th percentile $\mathrm{BaP}_{\text {eq }}$ concentration } & Exposure & 0.281 & 0.334 & 0.332 & 0.021 & 0.370 & 0.383 \\
\hline & Risk & $3.37 \times 10^{-6}$ & $4.01 \times 10^{-6}$ & $3.98 \times 10^{-6}$ & $2.47 \times 10^{-7}$ & $4.43 \times 10^{-6}$ & $4.59 \times 10^{-6}$ \\
\hline
\end{tabular}

a Carcinogenic risk using the SF value by CalEPA (2005).

${ }^{\mathrm{b}}$ Carcinogenic risk using the SF value by WHO (1987).

Table 3

Fitted distributions for exposure-risk model input variables.

\begin{tabular}{|c|c|c|c|c|}
\hline & Fitted distribution & Distribution parameters $^{\mathrm{a}}$ & $\mathbf{A D} \mathbf{D}^{\mathbf{b}}$ & $\mathbf{K S}^{\mathrm{c}}$ \\
\hline $\mathrm{BaP}_{\mathrm{eq}}$ gaseous phase concentration $\left(\mathrm{ng} / \mathrm{m}^{3}\right)$ & Lognormal & $\begin{array}{l}\text { Mean }=3.29 \\
S D=7.18\end{array}$ & 0.155 & 0.124 \\
\hline $\mathrm{BaP}_{\text {eq }}$ particle phase concentration $\left(\mathrm{ng} / \mathrm{m}^{3}\right)$ & Extreme value & $\begin{array}{l}\text { Mode }=24.20 \\
\text { Scale }=24.20\end{array}$ & 0.597 & 0.123 \\
\hline Body weight (kg) & Normal & $\begin{array}{l}\text { Mean }=73.31 \\
S D=12.82\end{array}$ & 0.439 & 0.095 \\
\hline Body surface area $\left(\mathrm{m}^{2}\right)$ & Normal & $\begin{array}{l}\text { Mean }=0.13 \\
S D=0.01\end{array}$ & 0.382 & 0.089 \\
\hline Sedentary activity (h/day) & Lognormal & $\begin{array}{l}\text { Mean }=3.34 \\
S D=1.54\end{array}$ & 0.236 & 0.081 \\
\hline Rest (h/day) & Extreme value & $\begin{array}{l}\text { Mode }=0.47 \\
\text { Scale }=0.78\end{array}$ & 1.027 & 0.121 \\
\hline Light activity (h/day) & Extreme value & $\begin{array}{l}\text { Mode }=0.84 \\
\text { Scale }=0.74\end{array}$ & 0.631 & 0.094 \\
\hline Heavy activity (h/day) & Normal & $\begin{array}{l}\text { Mean }=0.09 \\
S D=0.21\end{array}$ & 13.61 & 0.392 \\
\hline In transit (h/day) & Beta & $\begin{array}{l}\text { Alpha }=1.91 \\
\text { Beta }=9.31 \\
\text { Scale }=5.92\end{array}$ & 0.242 & 0.068 \\
\hline Inhalation chronic daily intake (ng/kg-day) & Gamma & $\begin{array}{l}\text { Scale }=2.42 \\
\text { Shape }=1.83\end{array}$ & 1.95 & 0.011 \\
\hline Dermal chronic daily intake (ng/kg-day) & Weibull & $\begin{array}{l}\text { Scale }=0.07 \\
\text { Shape }=1.79\end{array}$ & 1.509 & 0.027 \\
\hline
\end{tabular}

a SD: Standard deviation.

b AD: Anderson-Darling, test statistic values of $<0.5$ indicate a significant fit.

${ }^{\mathrm{c}} \mathrm{KS}$ : Kolmogorov-Smirnov, test statistic values of $<0.05$ indicate a significant fit.

Some of the PAHs have been classified as Group 1, 2A, and 2B carcinogens by International Agency for Research on Cancer (IARC) based on various levels of animal and human studies. Eight of the priority PAHs (16 PAHs listed by the USEPA, 2010) including BaA, $\mathrm{BaP}, \mathrm{BbF}, \mathrm{BkF}$, Chry, DahA, Ind, and Nap were classified as possible (2B) human carcinogens (IARC, 2004). In this study, 11 percent of the gaseous phase PAHs and 48 percent of the particle phase PAHs contained in ambient air were human carcinogens. Vu et al. (2011) analyzed PAH samples collected from downtown, residential, and industrial areas in Ulsan, Korea. Twenty to 45 percent of the total PAHs contained in $\mathrm{PM}_{10}$ was human carcinogens, with the highest fraction found in downtown area, whereas 55-80 percent of the total PAHs were not-classified or non-carcinogenic PAHs.

Five activity levels (rest, sedentary, light, moderate, and heavy activities) were considered in this study. The highest contribution to inhalation risks was from sedentary category (activities done sitting down) while the lowest was due to heavy activities such as playing football, aerobics, or doing heavy work such as digging soil. The assumed respiration rates for heavy and sedentary activities were $3.2 \mathrm{~m}^{3} / \mathrm{h}$ and $0.5 \mathrm{~m}^{3} / \mathrm{h}$, respectively (USEPA, 1997). However the average time spent with sedentary activities was 37 times higher than with heavy activities. In support, statistics show that 77 percent of $>14$ year-olds in Turkish population do not participate in sport activities (TUIK, 2007).

Results of the uncertainty analysis in the simulated exposure are shown in Table 4 as descriptive statistics for a chosen set of distribution percentiles and the mean. Relative standard deviation (RSD) was calculated as the measure of variation for an estimated population parameter. RSD values were $<4$ percent for the median, mean, and 95th percentile, whereas it was $\leq 12$ percent 

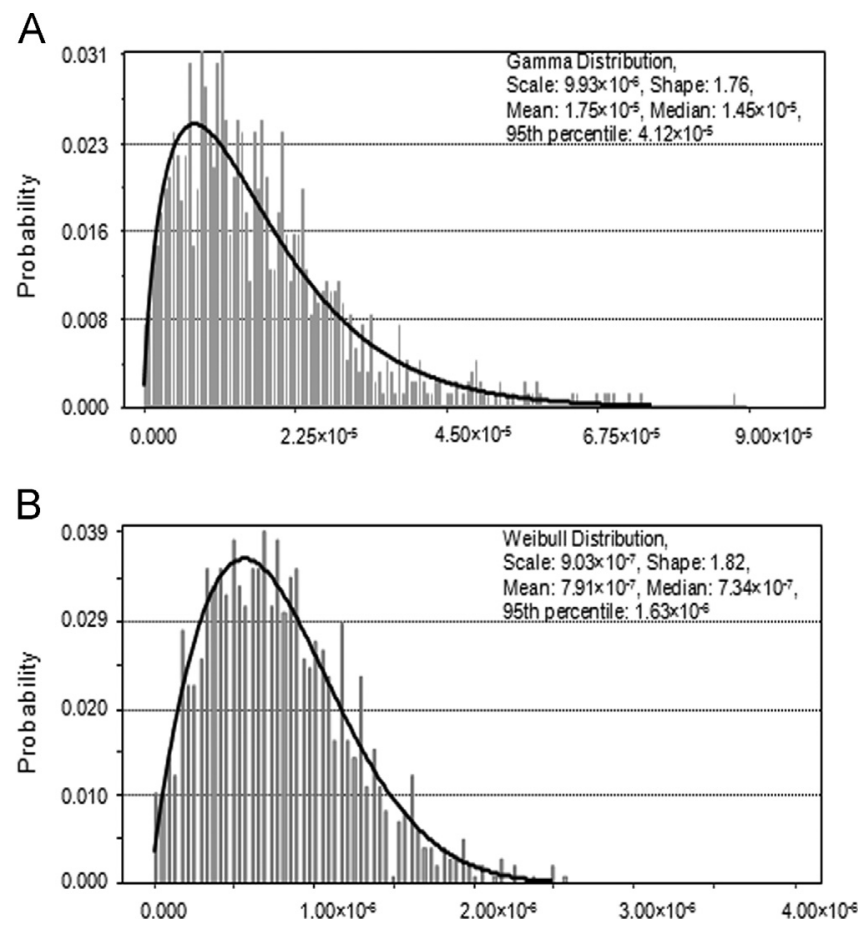

Fig. 2. Fitted probability distributions of cancer risk (a) based on SF by CalEPA (2005) for inhalation exposure, and (b) based on SF by CalEPA (2005) for dermal exposure.

Table 4

Uncertainty in distributional statistics of simulated exposure (ng/kg-day).

\begin{tabular}{llllll}
\hline $\begin{array}{l}\text { Exposure } \\
\text { type }\end{array}$ & Statistic & $\begin{array}{l}\text { 5th } \\
\text { Percentile }\end{array}$ & $\begin{array}{l}\text { 50th } \\
\text { Percentile }\end{array}$ & Mean & $\begin{array}{l}\text { 95th } \\
\text { Percentile }\end{array}$ \\
\hline Inhalation & Minimum & 0.394 & 3.537 & 4.109 & 10.430 \\
& Median & 0.623 & 3.773 & 4.393 & 11.622 \\
& Mean & 0.638 & 3.758 & 4.407 & 11.606 \\
& SD $^{\mathrm{a}}$ & 0.078 & 0.100 & 0.108 & 0.419 \\
& Maximum & 0.856 & 4.008 & 4.716 & 12.55 \\
Dermal & Minimum & 0.0071 & 0.0562 & 0.0619 & 0.1333 \\
& Median & 0.0092 & 0.06 & 0.0647 & 0.1436 \\
& Mean & 0.0097 & 0.0599 & 0.0648 & 0.1438 \\
& SD $^{\mathrm{a}}$ & 0.0011 & 0.0017 & 0.0011 & 0.0042 \\
& Maximum & 0.0127 & 0.0647 & 0.0682 & 0.1587 \\
\hline
\end{tabular}

a SD: Standard deviation.

for the 5th percentile for both of the exposure routes, indicating uncertainties arisen from the Monte Carlo process were low.

In this study, all PAH samples were collected during the heating period between October 2009 and March 2010. Limited number of studies that exist in literature have documented PAH concentrations in different seasons in Turkey. Esen et al. (2006) analyzed atmospheric samples which were collected between July 2004 and May 2005 in Bursa, Turkey. The measured average seasonal concentrations were $55 \pm 40,187 \pm 202,645 \pm 588$, and $148 \pm$ $132 \mathrm{ng} / \mathrm{m}^{3}$ for summer, fall, winter, and spring, respectively, which corresponds to a heating period (winter + fall)/non-heating period (summer + spring) ratio of $\sim 4$, and a winter to the average of the rest of the year ratio of $\sim 5$. Ari (2008) studied atmospheric PAH concentrations in Eskisehir, Turkey. The mean total PAH concentration in winter and summer was found as 1185 and $178 \mathrm{ng} / \mathrm{m}^{3}$, respectively. Hence, winter/summer ratio was about 7. The ratio of heating to non-heating period total PAH concentrations in Kocaeli was determined as $\sim 4$ (Gaga et al., 2012). The estimated inhalation exposures ranged between 0.037 and $24.4 \mathrm{ng} / \mathrm{kg}$-day, while the range for dermal exposure was from $3.70 \times 10^{-6}$ to $0.25 \mathrm{ng} / \mathrm{kg}$ day for the heating period in this study. If non-heating period exposures were to be roughly estimated by using the concentration ratio of four (Esen et al., 2006; Gaga et al., 2012), they would range between $9.25 \times 10^{-3}$ and $6.1 \mathrm{ng} / \mathrm{kg}$-day, and $9.25 \times 10^{-7}$ and $0.063 \mathrm{ng} / \mathrm{kg}$-day for inhalation and dermal exposures, respectively. Consequently, carcinogenic risks associated with chronic year-around inhalation and dermal exposures can be estimated as 1.25 folds of the risks estimated for the heating period.

In this study, two different SF values by CalEPA (2005) and WHO (1987) were used to calculate risk for inhalation. SF for inhalation exposure was estimated as $3.9(\mathrm{mg} / \mathrm{kg} \text {-day })^{-1}$ by CalEPA (2005). The $S F$ for inhalation was obtained on the basis of the data for respiratory tract tumors from inhalation exposure in hamsters. Also, a unit risk for $\mathrm{BaP}$ ( $\mathrm{UR}_{\mathrm{BAP}}$ ) was estimated to be $8.7 \times 10^{-5}$ per $\mathrm{ng} / \mathrm{m}^{3}$ based on epidemiological data from studies in coke-oven workers by WHO (1987). The UR $\mathrm{BaP}_{\mathrm{Ba}}$ is the calculated theoretical upper limit possibility of contracting cancer when exposed to BaP at a concentration of one microgram per cubic meter of air for a 70-year lifetime (CalEPA, 2005). When UR BAP was $_{3}$ converted to a slope factor, $S F$ for inhalation can be found as to 304.5 (mg/kg-day $)^{-1}$. The 95th percentile inhalation risk was calculated as $4.12 \times 10^{-5}$ by using SF by CalEPA (2005) which is higher than the general acceptable carcinogenic risk level of $10^{-6}$ but lower than the level of $10^{-4}$ applied for some pollutants such as arsenic, indicating considerable potential health risk. The 95th percentile inhalation risk calculated using SF by WHO (1987) is $3.33 \times 10^{-3}$, indicating high potential health risk. The difference in the $S F$ values is around two orders of magnitude due to assumptions and procedures which were applied to determine the $S F$ values. Hu et al. (2007) analyzed PAH samples for traffic policemen in Tianjin, China. They used a cancer slope factor of $3.14(\mathrm{mg} / \mathrm{kg} /$ day $)^{-1}$. The 95 th percentile risk value estimated by using a high average winter/summer ratio of PAH concentrations $(W=10)$ was $1.36 \times 10^{-4}$. Jia et al. (2011) conducted a study in Beijing, China. Samples of PAHs were collected in nonsource control and source control periods. The UR $\mathrm{BaP}_{\mathrm{B}}$ values by CalEPA (2005) and WHO (1987) were used to calculate risk for inhalation. The results showed that lifetime excess carcinogenic risk range from $6.5 \times$ $10^{-6}$ to $5.2 \times 10^{-4}$ for the source control period, and from $12 \times$ $10^{-6}$ to $9.6 \times 10^{-4}$ for the nonsource control period. In Turkey, Gaga et al. (2012) measured PAH compounds during heating and non-heating periods, and estimated associated carcinogenic risks for inhalation in an industrialized city, Kocaeli. The gas + particle phase PAH concentrations ranged from $6.2 \mathrm{ng} / \mathrm{m}^{3}$ (DahA) to $98.6 \mathrm{ng} / \mathrm{m}^{3}$ (PA) in the heating period, and from $3 \mathrm{ng} / \mathrm{m}^{3}(\mathrm{BaA})$ to $35.1 \mathrm{ng} / \mathrm{m}^{3}(\mathrm{PA})$ in the non-heating period. Unit risk of $8.7 \times 10^{-5}$ per $\mathrm{ng} / \mathrm{m}^{3}$ for a lifetime (70 years) exposure to BaP recommended by WHO (1987) was used to calculate cancer risk for the route of inhalation. The results showed that estimated total cancer risk levels were $2.92 \times 10^{-3}$ in the heating period and $1.15 \times 10^{-3}$ in the non-heating period. However, Gaga et al. (2012) estimated these risk levels using assumed values such as the mean values for the input variables except for the concentrations.

Two different $S F$ values for BaP dermal contact exposure were estimated as $37.47(\mathrm{mg} / \mathrm{kg} \text {-day })^{-1}$ based on incidence of skin tumors in mice (Schmahl et al., 1977) and 23.5 ( $\mathrm{mg} / \mathrm{kg}$-day) $)^{-1}$ based on a gastrointestinal absorption factor of 0.31 (Burmaster and Crouch, 1997; RAIS, 2006). These studies gave researchers guidance but there is no recommended $S F$ for BaP dermal contact exposure. An $S F$ value for ingestion exposure is recommended as $12.0(\mathrm{mg} / \mathrm{kg} \text {-day })^{-1}$ by CalEPA (2005). So, this value was used in our study to estimate carcinogenic risk for dermal exposure. The 95th percentile dermal risk was estimated as $1.63 \times 10^{-6}$ which is only a fraction higher than the general acceptable carcinogenic risk level. 
The estimated risks for inhalation route are at least an order of magnitude higher than those of dermal contact route. Consideration of only the particle-phase concentrations, low skin permeability, and small exposed surface area due to the season are the probable reasons for the difference between calculated risks for inhalation and dermal exposure routes. Chen and Liao (2006) estimated inhalation and dermal risks for adults, children, and infants in Taiwan, China. The geometric mean risk for inhalation and dermal exposure routes were reported as $1.04 \times 10^{-4}$ and $3.85 \times 10^{-5}$, respectively. The risks for adults are close to the values estimated in this study.

Sensitivity analysis was conducted to determine the influence of each input variable seperately for inhalation and dermal routes as the percent contribution to variance. Although there are slight differences, the contribution of gaseous phase $\mathrm{BaP}_{\text {eq }}$ concentration for inhalation risk estimated by the two SF values is around 90 percent as the most significant variable. The contribution of particle phase PAH concentration was the most influential variable with 93 percent for dermal contact. In other words, variation in the PAH concentrations is the largest source of variation in exposure-risk, therefore, they play the most important role in determining the exposure-risks.

\section{Conclusion}

Carcinogenic risk levels were assessed associated with dermal contact and inhalation of 19 PAH compounds in Balikesir during a heating period. The mean gaseous and particle phase concentrations were 432 and $187 \mathrm{ng} / \mathrm{m}^{3}$, respectively. Monte Carlo simulation was implemented to estimate exposure and carcinogenic risks via both routes of inhalation and dermal contact for Balikesir population in addition to the individual risks for the study participants. The estimated risks showed that inhalation exposure level is more significant than that of dermal contact route. The carcinogenic risks associated with inhalation reaches levels that are greater than the highest acceptable risk $\left(10^{-4}\right)$ when estimated using the SF by WHO (1987), while the risks for dermal contact were significantly lower. Sensitivity analysis suggests that the PAH concentrations play the most important role in determining the exposure-risks.

\section{Acknowledgement}

This study was supported by a grant (108Y166) from the Scientific and Technological Research Council of Turkey (TUBITAK). The authors thank Emin Taylan of Middle East Technical University, Ankara, Turkey, for the analysis of the samples.

\section{References}

Akcha, F., Burgeot, T., Narbonne, J.F., Garrigues, P., 2003. PAHs: An Ecotoxicological Perspective. Metabolic Activation of PAHs: Role of DNA Adduct Formation in Induced Carcinogenesis, 65-79 (P.E.T Douben)

Akyuz, M., Cabuk, H., 2008. Particle-associated polycyclic aromatic hydrocarbons in the atmospheric environment of Zonguldak, Turkey. Sci. Total Environ. 405, $62-70$.

Ari, A., 2008. Polycyclic Aromatic Hydrocarbons (PAHs) in Eskisehir Atmosphere, Concentrations and Source Apportionment. Anadolu University, Eskisehir, Turkey (in Turkish).

ATSDR, 1995. Toxicological Profile for Naphthalene, 1-Methylnaphthalene, and 2-Methylnaphthalene. U.S. Department of Health and Human Services, Public Health Service, Atlanta, GA.

Birgul, A., Tasdemir, Y., Cindoruk, S.S., 2011. Atmospheric wet and dry deposition of polycyclic aromatic hydrocarbons (PAHs) determined using a modified sampler. Atmos. Res. 101, 341-353.

Bozlaker, A., Muezzinoglu, A., Odabasi, M., 2008. Atmospheric concentrations, dry deposition and air-soil exchange of polycyclic aromatic hydrocarbons (PAHs) in an industrial region in Turkey. J. Hazard Mater. 153, 1093-1102.
Burmaster, D.E., Crouch, E.A., 1997. Lognormal distributions for body weight as a function of age for males and females in the United States, 1976-1980. Risk Anal. 17, 499-505.

CalEPA, 2005. Air Toxics Hot Spots Program Risk Assessment Guidelines. Part 2: Technical Support Document for Describing Available Cancer Potency Factors. Office of Environmental Health Hazard Assessment, Oakland, CA.

Callen, M.S., de la Cruz, M.T., Lopez, J.M., Murillo, R., Navarro, M.V., Mastral, A.M., 2007. Long-range Atmospheric Transport and Local Pollution Sources on PAH Concentrations in a South European Urban Area. Fulfilling of the European Directive.

Chang, K.F., Fang, G.C., Chen, J.C., Wu, Y.S., 2006. Atmospheric polycyclic aromatic hydrocarbons (PAHs) in Asia: a review from 1999 to 2004. Environ. Pollut 142, 388-396.

Chen, S.C., Liao, C.M., 2006. Health risk assessment on human exposed to environmental polycyclic aromatic hydrocarbons pollution sources. Sci. Total Environ 366, 112-123.

Delgado-Saborit, J.M., Stark, C., Harrison, R.M., 2011. Carcinogenic potential, levels and sources of polycyclic aromatic hydrocarbon mixtures in indoor and outdoor environments and their implications for air quality standards. Environ. Int 37, 383-392.

Demircioglu, E., Sofuoglu, A., Odabasi, M., 2011. Atmospheric concentrations and phase partitioning of polycyclic aromatic hydrocarbons in Izmir, Turkey. CleanSoil Air Water 39, 319-327.

Esen, F., Cindoruk, S.S., Taşdemir, Y., 2006. Ambient concentrations and gas/particle partitioning of polycyclic aromatic hydrocarbons in an urban site in Turkey. Environ. Forensics 7, 303-312.

Gaga, E.O., Ari, A., Dogeroglu, T., Cakirca, E.E., Machin, N.E., 2012. Atmospheric polycyclic aromatic hydrocarbons in an industrialized city, Kocaeli, Turkey: study of seasonal variations, influence of meteorological parameters and health risk estimation. J. Environ. Monit 14, 2219-2229.

Hanedar, A., Alp, K., Kaynak, B., Baek, J., Avsar, E., Odman, M.T., 2011. Concentrations and sources of PAHs at three stations in Istanbul, Turkey. Atmos. Res. 99 391-399.

Hu, Y., Bai, Z., Zhang, L., Wang, X., Zhang, L., Yu, Q., Zhu, T., 2007. Health risk assessment for traffic policemen exposed to polycyclic aromatic hydrocarbons (PAHs) in Tianjin, China. Sci. Total Environ. 382, 240-250.

IARC, 1983. Polynuclear aromatic compounds. Part 1: Chemical, environmental and experimental Data. In: IARC (Ed.), Monographs on the evaluation of carcinogenic risk of humans, Lyon, France, pp. 373-378.

IARC, 2004. Tobacco smoke and involuntary smoking. In: IARC (Ed.), Monographs on the evaluation of carcinogenic risk of humans, Lyon, France, pp. 1-1438.

IPCS, 1998. Environmental Health Criteria 202. Selected non-heterocyclic Polycyclic Aromatic Hydrocarbons. World Health Organization, International Programme on Chemical Safety, Geneva, Switzerland.

Jia, Y., Stone, D., Wang, W., Schrlau, J., Tao, S., Simonich, S.L., 2011. Estimated reduction in cancer risk due to $\mathrm{PAH}$ exposures if source control measures during the 2008 Beijing Olympics were sustained. Environ. Health Perspect 119, $815-820$.

Jung, K.H., Yan, B., Chillrud, S.N., Perera, F.P., Whyatt, R., Camann, D., Kinney, P.L. Miller, R.L., 2010. Assessment of benzo(a)pyrene-equivalent carcinogenicity and mutagenicity of residential indoor versus outdoor polycyclic aromatic hydrocarbons exposing young children in New York city. Int. J. Environ. Res. Public Health 7, 1889-1900.

Kaya, E., Dumanoglu, Y., Kara, M., Altiok, H., Bayram, A., Elbir, T., Odabasi, M., 2012. Spatial and temporal variation and air-soil exchange of atmospheric PAHs and PCBs in an industrial region. Atmos. Pollut. Res 3, 435-449.

Koc, T., 2001. Kuzeybatı Anadolu'da iklim ve ortam sinoptik, istatistik ve uygulama boyutları. Cantay Kitabevi, Istanbul, Turkey (in Turkish).

Larsen, J.C., Larsen, P.B., 1998. Chemical carcinogens. In: Hester, R.E., Harrison, R.M. (Eds.), Air Pollution and Health. The Royal Society of Chemistry, pp. 33-56.

Li, P.H., Kong, S.F., Geng, C.M., Han, B., Lu, B., Sun, R.F., Zhao, R.J., Bai, Z.P., 2013. Health risk assessment for vehicle inspection workers exposed to airborne polycyclic aromatic hydrocarbons (PAHs) in their work place. Environ. Sci. Processes Impacts 15, 623-632.

Livingston, E.H., Lee, S., 2001. Body surface area prediction in normal-weight and obese patients. Am. J. Physiol. Endocrinol. Metab. 281, E586-E591.

Luch, A., Baird, W.M., 2010. Carcinogenic polycyclic aromatic hydrocarbons, A. M. Editor-in-Chief: Charlene (Ed.), Comprehensive Toxicology, second ed. Elsevier, Oxford, pp. 19-96.

Malcolm, H.M., Dobson, S.J., 1994. The Calculation of an Environmental Assessment Level (EAL) for Atmospheric PAHs Using Relative Potencies. 34. Department of the Environment, London, UK, pp. 34-46.

Muller, P., 1997. Polycyclic aromatic hydrocarbons (PAH). Part 1: Hazard identification and dose response assessment. In: Scientific Criteria Document for Multimedia Environmental Standards Development Standards Development Branch, Ontario Ministry of Environment and Energy, Ontario, pp. 1-283.

Nisbet, I.C., LaGoy, P.K., 1992. Toxic equivalency factors (TEFs) for polycyclic aromatic hydrocarbons (PAHs). Regul. Toxicol. Pharmacol 16, 290-300.

OEHHA, 1994. Benzo(a)pyrene as a Toxic Air Contaminant. Part B. Health Assessment: Health Effects of Benzo(a)pyrene. Office of Environmental Health Hazard Assessment for the Air Resources Board, Sacramento, CA.

Ozcan, S., Aydin, M.E., 2009. Polycyclic aromatic hydrocarbons, polychlorinated biphenyls and organochlorine pesticides in urban air of Konya, Turkey. Atmos. Res. 93, 715-722.

Ozgunerge Falay, E., Tuna, G., Altiok, A., Kara, M., Dumanoglu, Y., Bayram, A. Tolunay, D., Elbir, T., Odabasi, M., 2013. Spatial variation of polycyclic aromatic 
hydrocarbons (PAHs) in air, soil and tree components in Iskenderun industrial region, Turkey. Int. J. Chem. Environ. Biol. Sci. 1, 263-267.

Petry, T., Schmid, P., Schlatter, C., 1996. The use of toxic equivalency factors in assessing occupational and environmental health risk associated with exposure to airborne mixtures of polycyclic aromatic hydrocarbons (PAHs). Chemosphere 32, 639-648.

Pufulete, M., Battershill, J., Boobis, A., Fielder, R., 2004. Approaches to carcinogenic risk assessment for polycyclic aromatic hydrocarbons: a UK perspective. Regul. Toxicol. Pharmacol 40, 54-66.

RAIS, 2006. Toxicity Profiles: Benzo[a]pyrene. Oak Ridge National Laboratory Risk Assessment Information System.

Rogge, W.F., Hildemann, L.M., Mazurek, M.A., Cass, G.R., Simoneit, B.R.T., 1993. Sources of fine organic aerosol. 2. Noncatalyst and catalyst-equipped automobiles and heavy-duty diesel trucks. Environ. Sci. Technol 27, 636-651.

Schmahl, D., Schmidt, K.G., Habs, M., 1977. Syncarcinogenic Action of Polycyclic Hydrocarbons in Automobile Exhaust Gas Condensates. IARC Scientific Publications, pp. 53-59.

Tagıl, S., 2004. Balıkesir ovası ve yakın çevresinin fiziki coğrafyası. Anıl Matbaa ve Ciltevi, Ankara, Turkey (in Turkish).

Tecer, L.K., Tuncel, G., Tuncel, S., Ozmetin, C., Sofuoglu, C.S., Ilten, N., 2012. Assessment of Concentrations, Sources, and Health Effects of Atmospheric Pollutants $\left(\mathrm{PM}_{2.5}, \mathrm{PM}_{10}, \mathrm{VOC}, \mathrm{PAH}, \mathrm{SO}_{2}, \mathrm{NO}_{2}, \mathrm{O}_{3}\right)$ and Indoor air Pollution in Province of Balikesir, and Dry and Wet Deposition of Heavy Metals to Drinkingirrigation Water Reservoir, İkizcetepeler (Project no: 108Y166). The Scientific and Technical Research Council of Turkey, Ankara, Turkey.

Tsai, P.-J., Shih, T.-S., Chen, H.-L., Lee, W.-J., Lai, C.-H., Liou, S.-H., 2004. Assessing and predicting the exposures of polycyclic aromatic hydrocarbons (PAHs) and their carcinogenic potencies from vehicle engine exhausts to highway toll station workers. Atmos. Environ 38, 333-343.

Turkish State Meteorological Service, 2014. Official Statistics: Balikesir Statistical Temperature Data. General Directorate of Turkish State Meteorological Service, Ankara, Turkey.
TUIK, 2007. Sports Statistics. Turkish Statistical Institute, Ankara, Turkey p. 2007. TUIK, 2010. Address Based Population Registration System. Census. Turkish Statistical Institute, Ankara, Turkey.

USEPA, 1992. Dermal exposure assessment: principles and applications. Office of Research and Development, Office of Health and Environmental Assessment/ OHEA, Washington, DC.

USEPA, 1997. Exposure Factors Handbook. Office of Research and Development, National Center for Environmental Assessment, US Environmental Protection Agency, Washington, DC.

USEPA, 2005. Guidelines for Carcinogen Risk Assessment. Risk Assessment Forum, US Environmental Protection Agency, Washington, DC.

USEPA, 2010. Development of a Relative Potency Factor (RPF) Approach for Polycyclic Aromatic Hydrocarbon (PAH) Mixtures (External Review Draft). US Environmental Protection Agency, Washington, DC.

Vu, V.T., Lee, B.K., Kim, J.T., Lee, C.H., Kim, I.H., 2011. Assessment of carcinogenic risk due to inhalation of polycyclic aromatic hydrocarbons in $\mathrm{PM}_{10}$ from an industrial city: a Korean case-study. J. Hazard. Mater 189, 349-356.

Westerholm, R., Li, H., 1994. A multivariate statistical-analysis of fuel-related polycyclic aromatic hydrocarbon emissions from heavy-duty diesel vehicles. Environ. Sci. Technol 28, 965-972.

WHO, 1987. Polynuclear Aromatic Hydrocarbons (PAH). Air Quality Guidelines for Europe. WHO Regional Office for Europe, Copenhagen, Denmark, pp. $105-117$.

Zhou, B., Zhao, B., 2012. Population inhalation exposure to polycyclic aromatic hydrocarbons and associated lung cancer risk in Beijing region: contributions of indoor and outdoor sources and exposures. Atmos. Environ 62, 472-480.

Zhou, B., Zhao, B., 2014. Analysis of intervention strategies for inhalation exposure to polycyclic aromatic hydrocarbons and associated lung cancer risk based on a Monte Carlo population exposure assessment model. PLoS One 9 (1), e85676. 